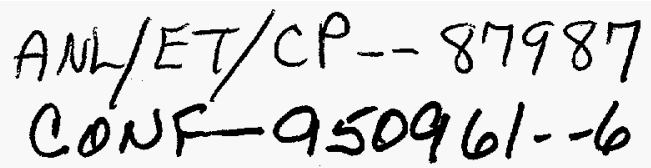

\title{
HYDROGEN TRANSPORT AND EMBRITTLEMENT FOR PALLADIUM COATED VANADIUM-CHROMIUM-TITANIUM ALLOYS*
}

\author{
R. E. Buxbaum, ${ }^{1}$ R. Subramanian, ${ }^{1}$ J.-H. Park, ${ }^{2}$ and D. L. Smith ${ }^{2}$ \\ ${ }_{1}$ REB Research and Consulting, Ferndale, MI 48220 \\ ${ }^{2}$ Argonne National Laboratory, Argonne, IL 60439

\section{JAN 241995 \\ OSTI} \\ RECEIVFD
}

\section{September 1995}

\begin{abstract}
The submitted manuscript has been authored by a contractor of the US Government under cont Accordingly, the U.S. Government retains a nonexclusive, royalty-free icense to publish or reproduce the published form of this contribution, or allow others to do so, for U.S.
\end{abstract}

Government purposes.

\section{DISCLAIMER}

\begin{abstract}
This report was prepared as an account of work sponsored by an agency of the United States Government. Neither the United States Government nor any agency thereof, nor any of their employees, makes any warranty, express or implied, or assumes any legal liability or responsibility for the accuracy, completeness, or usefulness of any information, apparatus, product, or process disclosed, or represents that its use would not infringe privately owned rights. Reference herein to any specific commercial product, process, or service by trade name, trademark, manufacturer, or otherwise does not necessarily constitute or imply its endorsement, recommendation, or favoring by the United States Government or any agency thereof. The views and opinions of authors expressed herein do not necessarily state or reflect those of the United States Government or any agency thereof.
\end{abstract}

Submitted to the Seventh International Conference on Fusion Reactor Materials (ICFRM-7), September 25-29, 1995, Obninsk, Russia.

*This work has been supported by the U.S. Department of Energy, Office of Fusion Energy Research, under Contract W-31-109-Eng-38. 


\section{HYDROGEN TRANSPORT AND EMBRITTLEMENT FOR PALLADIUM COATED} VANADIUM-CHROMIUM-TITANIUM ALLOYS

R. E. Buxbaum*, R. Subramanian*, J. H. Park\# and D. L. Smith\#

* REB Research and Consulting, 3259 Hilton Road, Ferndale, MI 48220, USA

\# Argonne National Laboratory, Fusion Power Program, 9700 S. Cass Ave., Argonne, IL 60439, USA

\section{Abstract}

As part of a study of the thermodynamics, kinetics and embrittlement properties of hydrogen in vanadium based alloys, experiments were conducted to determine the rate of hydrogen transport through the vanadium reference alloys, $\mathrm{V}$ $7.5 \mathrm{Cr}-15 \mathrm{Ti}$ and $\mathrm{V}-4 \mathrm{Cr}-4 \mathrm{Ti}$, and to determine these alloys' hydrogen embrittlement, they were exposed to hydrogen pressures of 3 and $300 \mathrm{kPa}(0.03-3 \mathrm{~atm})$ at temperatures between 380 and $475^{\circ} \mathrm{C}$. To facilitate hydrogen entry and egress, tubes of these alloys were coated with palladium on the inside and outside faces. Observed permeabilities were 0.015 to $0.065 \mu$ moles $/\left(\mathrm{m}^{2} \mathrm{sPa} 0.5\right)$ for the $\mathrm{V}-7.5 \mathrm{Cr}-15 \mathrm{Ti}$ alloy and 0.02 to $0.05 \mu \mathrm{moles} / \mathrm{m}^{2} \mathrm{sPa} 0.5$ for the $\mathrm{V}-4 \mathrm{Cr}-4 \mathrm{Ti}$ alloy depending on the quality of the coat and the operating temperature. At $1.7 \mathrm{~atm}$ hydrogen, $\mathrm{V}-7.5 \mathrm{Cr}-15 \mathrm{Ti}$ embrittled at temperatures below $380^{\circ} \mathrm{C}$ while $\mathrm{V}-4 \mathrm{Cr}-4 \mathrm{Ti}$ embrittled around $330^{\circ} \mathrm{C}$

\section{Introduction}

Vanadium based alloys have been identified as a leading candidate material for fusion first-wall blanket structure application because they exhibit favorable safety and environmental characteristics, good fabricability, potential for high performance and long-time operation lifetime in a fusion environment [1]. There are concerns with the vanadium based alloys though; 1) hydrogen isotopes may be transported too fast or too slowly, and 2) these alloys will embrittle when exposed to low temperatures and high hydrogen pressures e.g. during an injector malfunction. In this paper, the hydrogen transport and embrittlement properties of two reference vanadium alloys - one containing $7.5 \%$ chromium and $15 \%$ titanium ( $\mathrm{V}-7.5 \mathrm{Cr}-15 \mathrm{Ti})$ and another containing $4 \%$ Chromium and $4 \%$ titanium (V-4Cr-4Ti) are reported. The basis for the selection of these particular compositions are reported previously [1].

Several groups have demonstrated that the transport of hydrogen into and out of refractory metals can be improved by plating them with palladium, especially if the oxide barrier is removed [2-4]. In this case, palladium coat dissociated hydrogen molecules into atoms so that they can enter the vanadium and catalyze molecular reactivation when the hydrogen leaves. Palladium also protects the vanadium surface from small quantities of water vapor, oxygen or nitrogen that could otherwise present barriers to hydrogen entry and confound mechanical experiments.

\section{Theory}

Hydrogen transport through metals has been studied extensively [5-8]. Since hydrogen molecules dissociate into atoms to diffuse through metals, transport is calculated from the atomic flux. Fick's first law describes the flux of hydrogen atoms through a homogeneous phase as:

$$
\mathrm{NH}_{\mathrm{H}}=-D_{M}\left(\Delta \mathrm{C}_{\mathrm{H}} / d_{M}\right)
$$


where $\mathrm{NH}_{H}$ is the atomic flux, $D_{M}$ is diffusivity, $\Delta \mathrm{CH}_{H}$ is the change in hydrogen atom concentration across the membrane, and $d_{M}$ is the membrane thickness. $\mathrm{C}_{H}$ is related to the partial pressure of hydrogen in equilibrium with the metal, correlated for example by

$$
\mathrm{CH}_{\mathrm{H}}=\mathrm{KS}(\mathrm{p} 1 / 2)
$$

where KS, is the Sieverts constant, and $\mathrm{P}$ is the partial pressure of hydrogen in equilibrium with the metal. The power of $1 / 2$ comes from the dissociation of hydrogen molecules into twice as many atoms at low concentration.

We now calculate the flux of hydrogen molecules, $\mathrm{N}$, in terms of pressure using equations 1 and 2 . Since the flux of molecules is half the flux of atoms:

$$
\begin{aligned}
& N \quad=\left(D_{M K S} / 2 d_{M}\right) \Delta \mathrm{P}^{1 / 2} \\
& =P_{M} \Delta \mathrm{p}^{1 / 2 / d_{M}} .
\end{aligned}
$$

The term $P_{M}$ above is called the metal permeability,

$$
P_{M}=D_{M} K_{S} / 2
$$

a pressure-independent constant for a given metal at low hydrogen contents. Two derived quantities, the 'permeance' and the 'total resistance to transport' are respectively, the flux divided by the pressure driving force, and the inverse of this number. These numbers are related to the average permeability, $\boldsymbol{P}$.

$$
\begin{array}{lll}
\text { Permeance } & \equiv \mathrm{N} / \Delta \mathrm{P}^{1 / 2}=P / d \\
\mathbf{R}_{\text {Tot }} & \equiv \Delta \mathrm{P}^{1 / 2} / \mathrm{N}=d / \mathrm{P} .
\end{array}
$$

In the absence of gas-phase mass transfer resistance, the total transport resistance of a membrane is the sum of the resistance in each layer [9]. These equations are used to calculate the permeability and resistance to hydrogen transport $[10,11]$.

\section{Experimental}

$\mathrm{V}-7.5 \mathrm{Cr}-15 \mathrm{Ti}$ had an outer diameter of $0.75 \mathrm{~cm}$, and a wall thickness of $0.04 \mathrm{~cm}$ while $\mathrm{V}-4 \mathrm{Cr}-4 \mathrm{Ti}$ had an outer diameter of $0.457 \mathrm{~cm}(0.18$ inches $)$ and a wall thickness of $0.0254 \mathrm{~cm}(0.01$ inches $)$. They were coated as per the procedure of Buxbaum and Hsu [12].

The permeabilities of the palladium coated membranes were measured using the apparatus shown in Figure 1. A detailed description of the apparatus is given elsewhere [10]. The membrane was held in place by swagelock fittings which concealed $1 / 4^{\prime \prime}$ of the membrane at each end. The flows of the various gas streams are shown in the figures. The input hydrogen or hydrogen-argon enters the apparatus and is heated up to the operating temperature, then comes down the inside of the apparatus and contacts the membrane. Much of the hydrogen permeates through the membrane, and the rest exits along with the argon. The flow rate of hydrogen through the membrane, and the gas pressures inside and outside the membrane were measured. From this and knowing the membrane surface area, the effective permeance of the membrane was calculated using Equation 5 . All other parameters can then be calculated from the equations given in the theory section. A 
total of $4 \mathrm{~V}-7.5 \mathrm{Cr}-15 \mathrm{Ti}$ and $5 \mathrm{~V}-4 \mathrm{Cr}-4 \mathrm{Ti}$ membranes, each about $2-3$ inches long, were coated and tested for hydrogen flux.

\section{Results and Discussion}

The $\mathrm{V}-7.5 \mathrm{Cr}-15 \mathrm{Ti}$ membranes were subject to pressures ranging from $0.03-3$ atm, and a temperature range of 380 to $475^{\circ} \mathrm{C}$. Fluxes of these membranes ranged from 0.54 to $1.79 \mathrm{moles} /\left(\mathrm{m}^{2} \mathrm{~min}\right)$ for pressures drops averaging one atmosphere and permeabilities from 0.015 to $0.065 \mu$ moles $/\left(\mathrm{m}^{2} \mathrm{sPa} 0.5\right)$ depending on the quality of the coat and temperature. Figure 2 shows a graph of the $\ln (P)$ vs. $1 / T$. Note that embrittlement occurred only at lower temperatures. Synthesis gas was successfully passed through this membrane at $430^{\circ} \mathrm{C}$ and the membrane showed no signs of poisoning or embrittlement.

$\mathrm{V}-4 \mathrm{Cr}-4 \mathrm{Ti}$ alloy had higher permeabilities and a lower tendency to embrittle than $\mathrm{V}-7.5 \mathrm{Cr}-15 \mathrm{Ti}$ alloy. The fluxes for this alloy ranged from 0.65 to 1.88 moles $/ \mathrm{m}^{2} \mathrm{~min}$ for pressure drops of 1 atmosphere, and the permeabilities ranged from 0.02 to $0.05 \mu$ moles $/ \mathrm{m}^{2} \mathrm{sPa} 0.5$ over a temperature range of 450 to $370^{\circ} \mathrm{C}$. Figure 2 shows a graph of the $\ln (P)$ vs. 1/T. In one experiment the temperature was dropped steadily to $345^{\circ} \mathrm{C}$ from $445^{\circ} \mathrm{C}$, while holding the pressure constant at $10 \mathrm{psig}$. Over this temperature range the flux dropped $25 \%$ but the alloy maintained its structural integrity. When the temperature was dropped to $330^{\circ} \mathrm{C}$, the tube cracked. In a similar experiment with the V-7.5Cr-15Ti alloy, the pressure was maintained at 9 psig, and the temperature was dropped from 475 to $390^{\circ} \mathrm{C}$ during which the flux dropped $50 \%$. When the membrane was heated back to $420^{\circ} \mathrm{C}$, the flux reached its former value. When the temperature was dropped again to $380^{\circ} \mathrm{C}$ while maintaining the pressure at 21.1 psig, the flux again dropped $50 \%$.

The permeabilities of both these membranes decreases with decreasing temperature as seen in Figure 2. Such a trend has been seen for palladium coated tantalum and niobium [10] and for palladium coated vanadium-nickel alloys [13]. One cause of this decrease in flux is transport resistance in the palladium coat and this resistance decreases with increasing temperature. It has also been suggested [14] that as temperatures rise, the hydrogen content decreases, and this increases the diffusion rates by increasing the number of vacant sites next to the hydrogen atoms. These two reasons could cause the increase in membrane permeability with rising temperature for the given pressures.

A surprising observation was that these alloys expand as much as $4.5 \%$. On absorption of stoichiometric hydrogen, pure vanadium expands only $2.8 \%$ [15].

\section{Conclusions}

The V-4Cr-4Ti alloy also had higher fluxes than V-7.5Cr-15Ti for the conditions studied but both alloys had high permeabilities and high fluxes over pressure drops averaging one atmosphere and temperatures ranging from 450 to $380^{\circ} \mathrm{C}$. If these permeabilities persist to lower pressures, cooling will be needed for any fusion reactor use to prevent excess tritium leakage. Of the two alloys, $\mathrm{V}-4 \mathrm{Cr}-4 \mathrm{Ti}$ seems somewhat less embrittling, but both alloys are less embrittling than niobium alloys that had been considered for early fusion reactor designs. The embrittling characteristics of both these alloys are probably acceptable for fusion reactor use. 


\section{References}

[1] D. L. Smith, H. M. Chung, B. A. Loomis, H. Matsui, S. Votinov and W. van Witzenburg, Fusion Eng. Des. 29 (1995) 399.

[2] R. E Buxbaum and P. C. Hsu, J. Nucl. Mater. 189 (1992) 183.

[3] E. F. Hill, Feasibility Study: Removal of Tritium form Sodium during the MDEC Process by Oxidative Diffusion, Argonne West, DOE N707T1830035 (1982).

[4] H. Uchida and E. Fromm, J. Less Comm. Met. 95 (1983) 153.

[5] S. A. Steward, Review of Hydrogen Isotope Permeability through Materials, Lawrence Livermore National Laboratory Report UCRL-53441 (1983).

[6] M. A. Pick, J. W. Davenport, M. Strongin and G. J. Dienes, Phys. Rev. Lett. 43 (1979) 286.

[7] R. Hemplelmann, J. Less Comm. Met. 101 (1984) 69.

[8] J. E. Kliener, E. H. Sevilla and R. M. Cotts, Phys. Rev. B 33 (1986) 6662.

[9] R. E Buxbaum, Sep. Sci. Tech. 18 (1983) 1251.

[10] R. E. Buxbaum and A. B. Kinney, Ind. Eng. Chem. Res. (1995, in press).

[11] R. E. Buxbaum and T. L. Marker, J. Membr. Sci. 89 (1993) 29.

[12] R. E Buxbaum and P. C. Hsu, Method of Plating Palladium, U. S. Patent $5,149,420$, Sept. 22, 1992.

[13] M. Amano, M. Kowaski and C. Nishimura J. Less Comm. Met. 172-174 (1991) 727.

[14] D. T. Peterson and C. L. Jensen Met. Trans. A. 11A (1980) 627.

[15] W. M. Mueller, J. P. Blackledge and G. C. Kibowitz, Metal Hydrides, (Academic press, New York, 1968). 


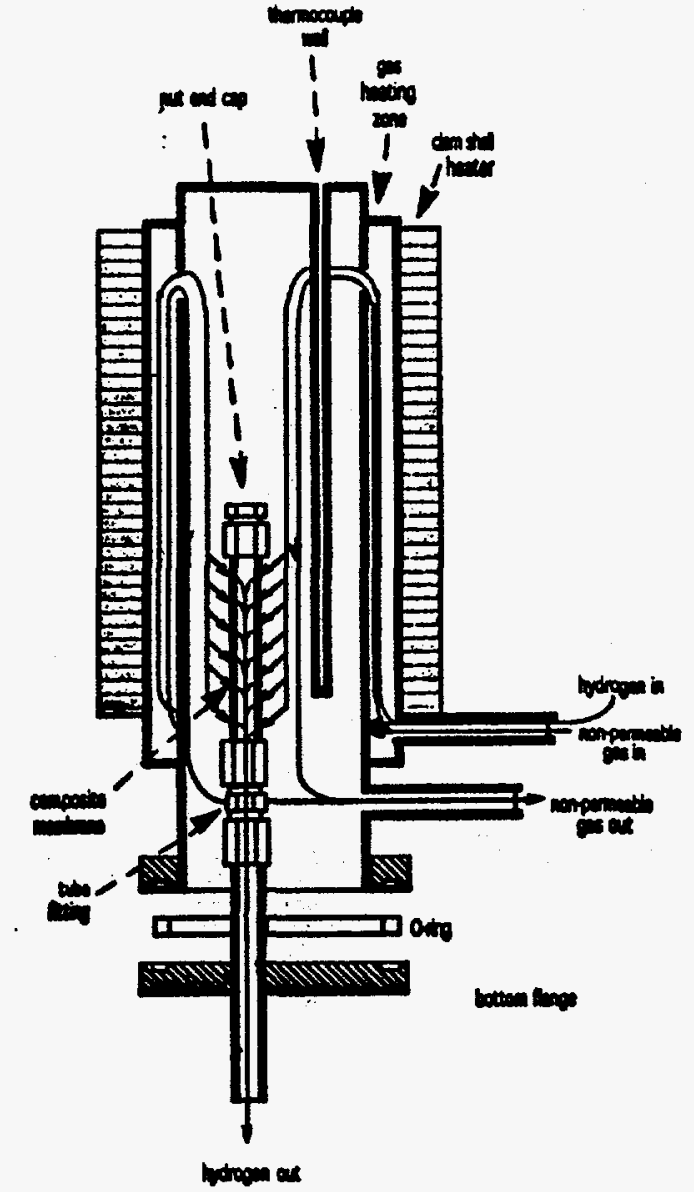

Figure 1: Hydrogen Permeation Apparatus

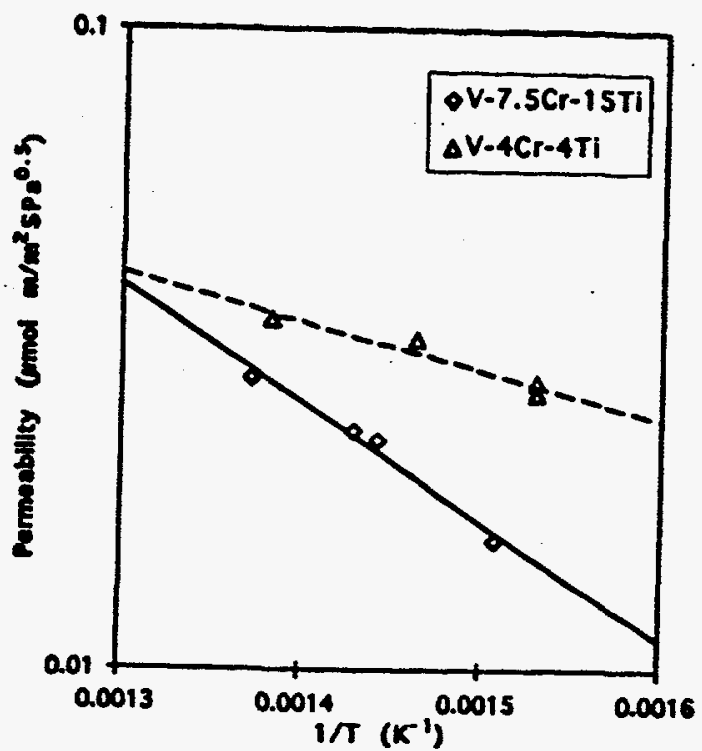

Figure 2: Permeability of the alloys with inverse temperature 